\title{
Parent-offspring interactions in a long-lived seabird, the Little Auk (Alle alle): begging and provisioning under simulated stress
}

\author{
D. Kidawa ${ }^{1}$ (D) $\cdot$ M. Barcikowski ${ }^{1}$ R. Palme ${ }^{2}$
}

Received: 3 May 2016/Revised: 7 July 2016/Accepted: 28 July 2016/Published online: 9 August 2016

(c) The Author(s) 2016. This article is published with open access at Springerlink.com

\begin{abstract}
Long-lived seabirds are good models to study the mechanisms that mediate the parent-offspring interactions. Contrary to studies under natural conditions, experimental manipulations allow us to assess the birds' reactions in a short time period. We used the stress hormone corticosterone as an independent experimental factor to simulate the stress reaction, to examine changes in the behaviour of Little Auk chicks and parent birds. In the first experiment, we hypothesised that after enhancement of the corticosterone level Little Auk (Alle alle) chicks intensify their begging performance and attain a higher pre-fledging body mass than the control chicks. In the second experiment, we hypothesized that parent Little Auks with an increased corticosterone level feed their chicks less frequently and spend less time at the colony than their untreated partners and the control birds. We also expected that chicks with one parent implanted with corticosterone fledge later and with a lower body mass than chicks of two untreated parents. The obtained results supported the above hypotheses. We demonstrated that modification of begging performance in Little Auks constitutes an adaptive mechanism that guards against the decrease in the chicks' body condition during stressful periods. Even though the provisioning rate in Little Auks can be regulated according to the chick's needs (expressed by the intensity of the begging
\end{abstract}

Communicated by C. Barbraud.

D. Kidawa

dorotakidawa@univ.gda.pl

1 Department of Vertebrate Ecology and Zoology, University of Gdańsk, ul. Wita Stwosza 59, 80-308 Gdańsk, Poland

2 Department for Biomedical Sciences, University of Veterinary Medicine, Veterinärplatz 1, 1210 Vienna, Austria display), it appears that adult birds regulate their provisioning strategy primarily according to their body state. The results suggest that parent Little Auks under stressful conditions will decrease their parental effort and redirect the available energy towards self-maintenance. The study provides novel insights into the behaviour of long-lived alcids using an experimental approach on free-living birds.

Keywords Begging · Provisioning - Chick growth . Corticosterone $\cdot$ Alle alle $\cdot$ Arctic

\section{Zusammenfassung}

Eltern-Nachwuchs Interaktionen bei einem langlebigen Seevogel, dem Krabbentaucher (Alle alle): Betteln und Versorgen bei simuliertem Stress

Langlebige Meeresvögel eignen sich gut, um Mechanismen der Eltern-Nachwuchs Interaktion zu untersuchen. Im Gegensatz zu Studien unter natürlichen Bedingungen erlauben experimentelle Manipulationen, die unmittelbare Reaktion der Vögel zu messen. Wir verabreichten das Stresshormon Kortikosteron zur Simulierung einer Stressreaktion und, um Verhaltensänderungen bei Eltern- und Jungtieren zu beobachten. Die Hypothese im ersten Experiment war, dass Küken mit erhöhtem Kortikosteronspiegel ihr Bettelverhalten intensivieren und schwerer werden als die Kontrolltiere. Im zweiten Experiment postulierten wir, dass Eltern mit erhöhtem Kortikosteronspiegel ihren Nachwuchs seltener füttern und weniger Zeit in der Kolonie verbringen als ihre unbehandelten Partner bzw. Kontrolltiere. Wir erwarteten auch, dass Küken von Paaren, in denen ein Elternteil mit einem Kortikosteronpellet implantiert war, später schlüpfen und dabei leichter sind als Küken von unbehandelten Eltern. Die Ergebnisse unserer 
Experimente unterstützten unsere Hypothesen. Wir konnten zeigen, dass die Modifikation des Bettelverhaltens beim Krabbentaucher ein adaptiver Mechanismus ist, der einer Verschlechterung der Verfassung während Stressperioden entgegenwirkt. Obwohl die Versorgungsrate beim Krabbentaucher entsprechend dem Bedürfnis der Küken (ausgedrückt durch die Intensität des Bettelverhaltens) reguliert werden kann, scheinen erwachsene Vögel ihre Versorgungsstrategie primär nach ihrer Körperverfassung auszurichten. Die Ergebnisse legen nahe, dass Krabbentaucher in Belastungssituationen ihre elterliche Fürsorge reduzieren und die verfügbare Energie in Richtung Selbsterhalt umlenken. Die Studie liefert neue Einsichten in das Verhalten langlebiger Alken unter Verwendung eines experimentellen Ansatzes bei freilebenden Vögeln.

\section{Introduction}

The allocation of resources between parents and offspring is particularly important for long-lived species. Under limited resources, long-lived parent birds are expected to safeguard their own body condition, rather than to invest in current reproductive output (Ricklefs 1977; Stearns 1992). Thus, a degree of parental investment should be determined primarily by the parents' physiological state and their prospects of survival, whereas chicks may attempt to solicit more food by intensifying their begging performance. In honest signalling, begging displays incorporate information about a chick's energy requirements or chick state, and parents use this as a signal to adjust their provisioning rate accordingly (Cotton et al. 1996). Both begging behaviour and parental provisioning strategies can be determined by fluctuations in the environment, which affect birds during their breeding period. When resources are severely limited, chicks compete with their future siblings.

Seabirds, which are characterised by long life spans, late maturity, and a low annual reproductive output, are good models to study the mechanisms that mediate the parentoffspring conflict. The Little Auk (Alle alle) is an Arctic seabird that exhibits one of the highest mass-specific daily energy expenditures and daily weight gain among the Alcidae and other seabird species of similar body mass (Konarzewski et al. 1993; Stempniewicz 2001). A single semi-precocial chick is raised annually, in a nest concealed under the surface, in extensive boulder screes on mountain slopes (Stempniewicz 2001). The chick remains in the nest for 4 weeks (Stempniewicz 1981; Wojczulanis-Jakubas and Jakubas 2012) and both parents contribute equally to chick provisioning (Stempniewicz and Jezierski 1987) until the final week of chick rearing, when some females disappear from the colony 1-3 days before the chicks fledge
(Harding et al. 2004; Wojczulanis-Jakubas and Jakubas 2012). Parent birds might be flexible and adjust their provisioning efforts to variable trophic conditions. Some studies have suggested that Little Auks can compensate for a lower quality of food by increasing the number of feedings (Jakubas et al. 2007; Kwasniewski et al. 2010), whereas others documented a decreased provisioning rate under deteriorated foraging conditions (Welcker et al. 2009; Kidawa et al. 2015). The inconsistency of these results is difficult to explain in natural conditions. Studies on other seabirds, such as the Common Guillemot Uria aalgae or Atlantic Puffin Fratercula arctica, also demonstrated that adult birds invested more energy to buffer nestlings from the consequences of reduced prey availability (Burger and Piatt 1990; Eilertsen et al. 2008).

Contrary to environmental changes, which are slow and difficult to forecast, experimental conditions allow us to predict the birds' response in a short time period. Variable demands of the life cycle, as well as unpredictable and lifethreatening perturbations in the environment activate the hypothalamic-pituitary-adrenal axis (Möstl and Palme 2002; Romero 2002; Landys et al. 2006). This results in enhancing the secretion of glucocorticoids, which are the front-line hormones that participate in an organism's response to stress (Möstl and Palme 2002). A high level of corticosterone, which is the main stress hormone in birds, has been suggested to be a reliable indicator of poor condition or health, thus, reflecting how an individual copes with the environment (Bonier et al. 2009). In Little Auks, a higher corticosterone level might also be associated with food deprivation or unfavourable weather conditions (Kidawa et al. 2014). Therefore, corticosterone could be used as an established hormonal indicator of an organism's response to stress, but also as an independent experimental factor that simulates the stress reaction (Kitaysky et al. 2001; Romero et al. 2005; Müller et al. 2009a; Shini et al. 2009; Spée et al. 2011). Experimental manipulations appear to be the best way to predict birds' reactions during unfavourable environmental conditions. The recognised positive corticosterone response to adverse trophic and environmental conditions (Harding et al. 2011; Kidawa et al. 2014) allowed us to artificially enhance the corticosterone level in Little Auk chicks and adult birds, to study changes in their behaviour.

In the first experiment, we studied changes in the begging performance and growth of Little Auk chicks following an experimental increase in the circulating corticosterone levels. We hypothesised that Little Auk chicks intensify their begging in response to increased corticosterone levels and attain a higher pre-fledging body mass than the control chicks. Single-chick broods of Little Auk provide an opportunity to study the role of begging signals in a parent-offspring conflict, without the effect of 
sibling competition. Moreover, the role of hormones as regulators of offspring begging performance varies among different bird species (Smiseth et al. 2011), and the begging behaviour of Little Auk chicks has not been studied to date. Changes in begging performance in relation to increased corticosterone levels have been studied mostly in birds with more than one offspring (Kitaysky et al. 2001; Vallarino et al. 2006; Loiseau et al. 2008). Some studies of species with single-chick broods reported contrasting results, with no relationship between corticosterone secretion and begging behaviour in the Tufted Puffin Fracetula cirrhata (Williams et al. 2008) or a positive correlation in the Thin-billed Prion Pachyptila belcheri (Quillfeldt et al. 2006).

In the second experiment, we investigated changes in the chick provisioning rate and the time spent at the colony by Little Auk parent birds with experimentally increased levels of circulating corticosterone, as well as the growth of their chicks. We hypothesised that adult birds with an increased corticosterone level feed their chicks less frequently and spend less time at the colony than their untreated partners and the control birds. We also expected that chicks with one parent implanted with corticosterone fledge later and with a lower body mass than chicks of two untreated parents. Due to the evident linkage between body condition and survival (Harding et al. 2011), adult birds should govern the degree of parental investment against the negative consequences on their own body condition. Exploring the mechanisms that regulate the parental investment might help to evaluate the trade-offs involved in the reproductive performance in Little Auks, which are particularly important in predicting their response to the worsening foraging conditions in the Arctic (Karnovsky et al. 2010; Kwasniewski et al. 2012).

\section{Methods}

We carried out the study in the Little Auk breeding colony on the Ariekammen slopes in Hornsund (SW Spitsbergen; $77^{\circ} 00^{\prime} \mathrm{N}, 15^{\circ} 33^{\prime} \mathrm{E}$ ), which constitutes one of the main breeding areas of Little Auks in Svalbard (Isaksen 1995). We conducted field experiments during two breeding seasons: in July to August in 2012 we carried out experimental manipulations with chicks, and in July to August in 2013 we carried out experimental manipulations with parent birds. Nests were located on mild talus slopes, with breeding densities of ca $1.6 \mathrm{birds} / \mathrm{m}^{2}$. In both study years during the period of hatching, we were examining 50 Little Auk nests every 2 days to determine the precise ( \pm 1 day) day of hatching of each chick. We ceased regular nest inspections after hatching, to prevent disturbance to provisioning parents until the second week of the chicks' life.
We chose nests with chicks of similar hatching date ( \pm 1 day) for the studies.

\section{Experiment with chicks}

In the first experiment, we implanted 15 Little Auk chicks of the same age (10-12th day of life) with self-degradable, corticosterone-releasing pellets (Innovative Research of America, Sarasota, FL, USA; $7.5 \mathrm{mg}$ corticosterone, 7-day release). Additionally, we implanted three chicks with a placebo pellet. We placed the pellets under the skin on the neck through a small incision $(\mathrm{ca} 0.3 \mathrm{~cm})$, which we closed with tissue adhesive (Surgibond, SMI AG Germany). The experimental treatment did not affect the survival of chicks. Previous studies have shown that exogenous corticosterone administration effectively increases the corticosterone level in birds (Kitaysky et al. 2001; Romero et al. 2005; Bourgeon and Raclot 2006; Angelier et al. 2009; Müller et al. 2009a, b; Spée et al. 2011). For example, Spée et al. (2011) observed a 3.3-fold increase in circulating corticosterone levels within 3 days of pellet implantation. We chose chicks with a similar body mass for the study, because corticosterone levels vary between individuals with respect to their body mass (Kidawa et al. 2014).

To investigate changes in the begging performance after corticosterone implantation, we recorded chicks twice: 1 day before the manipulation and 2 days after the corticosterone implantation. We placed miniature microphones, connected to recorders via a 1-m-long cable, inside the burrows. We set up dictaphone voice recorders (OLYMPUS Recorders) to run for at least $10 \mathrm{~h}$ with a sampling rate of $44 \mathrm{kHz}$. During the Little Auks' breeding period, a polar day provides continuous daylight and parents feed their chicks for $24 \mathrm{~h}$. Chicks often called in the absence of parents, and usually showed increased acoustic activity when one of the parents entered the burrow. The number of feedings registered in the voice recorders was similar during both recording sessions (on average four feedings during $10 \mathrm{~h}$ of recordings). In total, we analysed $240 \mathrm{~h}$ of recordings using Raven Pro 1.5 (Bioacoustics Research Program 2013). We located the begging sessions (i.e., series of begging calls with a pause not longer than $10 \mathrm{~s}$ ) visually on spectrograms and waveforms. We measured the length of the begging session (s) and intervals between begging sessions (s) in Raven's waveform and spectrogram views. We calculated the rate of calling (calls per min) within each begging session using Raven's Band Limited Energy Detector (Charif et al. 2010).

In order to compare the growth of corticosterone-implanted (experimental) chicks with that of unmanipulated chicks of the same age (control group), we weighed chicks with an electronic balance (OHAUS, accurate to $0.1 \mathrm{~g}$ ). We compared the body masses of chicks at the initial stage of 
the experiment ( 3 days after implantation, when chicks were 13-15 days old), prior to chick fledging, as well as the day of life when the chicks left the colony.

\section{Experiment with parent birds}

In the second experiment, we captured adult birds in their nests while brooding their newly hatched chick (1-3 days after the chick hatched). We ringed birds or recorded the ring number for birds already carrying a metal ring. We marked all birds with combinations of colour rings, and colour marks dyed on their breasts, weighed using a PESOLA $^{\circledR}$ balance $( \pm 1.0 \mathrm{~g})$, and measured (head-bill length) using callipers $( \pm 0.1 \mathrm{~mm})$. The marking patterns enabled the rapid identification of each bird in the field. We chose birds with a similar body mass and similar chick hatching date for the study. We implanted twelve parents (one member of the breeding pair) with corticosterone-releasing pellets (Innovative Research of America, Sarasota, FL, USA; $15 \mathrm{mg}$ corticosterone, 7-day release), in the same way as chicks in the previous experiment. Partners of experimental birds $(n=10)$ and control birds $(n=18)$ underwent the same protocol, but without pellet insertion. Overall, the manipulation lasted for 10-15 min for controls and 15-25 min for experimental birds. We started $24 \mathrm{~h}$ continuous observation $48 \mathrm{~h}$ after the corticosterone implantation, when we expected the corticosterone boost. Capture, handling, and restraint procedures could affect the stress response in both, experimental and control birds. Moreover, pellet implantation in experimental birds was an additional short-term stressor. We have not used sham incision or placebo pellets here, thus, we are unable to distinguish between the effect of corticosterone pellets and the additional stress made by implantation itself. However, the pellets were continuously releasing a consistent dose of hormone resulting in long-term hormone elevation, while our activities were short-term stressors. Behavioural observations started $48 \mathrm{~h}$ after the corticosterone implantation, to allow recovery from manipulation stress. The nest sites of all observed birds were situated in close proximity to each other, to allow observers to monitor the whole colony patch and not to disturb the birds. We monitored the presence of birds continuously and recorded all arrivals with/without food to the nest and departures from the colony. All birds returned to the colony after manipulation.

We measured the body mass of chicks with a corticosterone-implanted parent and control chicks with an electronic balance (OHAUS, accurate to $0.1 \mathrm{~g}$ ). We compared the body masses in the middle of the nesting period, when chicks were 14-15 days old (the end of the second week of the experiment) and prior to fledging (the end of the fourth week of the experiment).

\section{Evaluating the corticosterone level after implantation}

To monitor corticosterone levels after pellet implantation, we measured the concentration of corticosterone metabolites in faeces, which is a valuable non-invasive method to examine hormone levels and has been successfully validated for Little Auks (Kidawa et al. 2014). We collected faeces immediately in plastic tubes, labelled and maintained in a field cooler box with frozen gel packs for up to $1 \mathrm{~h}$, and then we stored them in a freezer at $-20^{\circ} \mathrm{C}$ until analysis. During the laboratory analyses, we thawed samples, mixed with $60 \%$ methanol (proportion: 1:10) and vortexed for $30 \mathrm{~min}$ (Palme et al. 2013). After centrifugation, we transferred the supernatant to a new tube and used for analysis with an 11-oxoaetiocholanolone enzyme immune assay (EIA; for details of the performed EIA see Palme and Möstl 1997; Möstl et al. 2002). We measured faecal corticosterone metabolites in chicks before the manipulation (we obtained the sample just before pellet implantation) and 3 days after corticosterone implantation. We could not monitor the corticosterone level during the initial days after implantation, when we expected the corticosterone boost and made the recordings in the nests, because capture would risk affecting the chicks' begging behaviour. We also collected faecal samples from the control, non-manipulated chicks at a similar age. We did not monitor the corticosterone level in adult birds during the experiment to prevent disturbance to provisioning parents.

\section{Statistics}

We carried out statistical analyses in R 3.2.2 (R Core Team 2015). We applied the two-sample Wilcoxon rank-sum test, also known as the Mann-Whitney test, and the Kruskal-Wallis test when the data did not meet the assumptions of the parametric test (i.e., the level of faecal corticosterone metabolites, body mass measurements in chicks, provisioning rates, and time spent at the colony). For pairwise comparisons we used the Tukey and Kramer (Nemenyi) test with the Tukey-Dist approximation for independent samples (Pohlert 2014).

To compare begging intensity before and after corticosterone manipulation, we analysed the following variables: (1) the number of calls per minute, (2) the length of begging sessions, and (3) the length of intervals between begging sessions with a particular chick as a random effect. We transformed the length of intervals using the Box-Cox method to correct for skewness. We performed analyses using the MCMCglmm package of R software (Hadfield 2010; R Core Team 2015). This test is appropriate for 
paired samples, since it recognises repeated measures (before and after treatment) in each chick. Additionally, we performed an extended MCMCglmm analyses: (1) to check whether individual chicks reacted differently to corticosterone manipulation, we added interaction between the random factor (chick) and the fixed factor (experiment); (2) to check whether the effect of the chick was the same before and after manipulation, we added the covariance between the variables. The MCMCglmm analysis uses a Markov chain Monte Carlo (MCMC) estimation approach and is based on the use of Bayesian inference, with prior distributions of unknown parameters. MCMCglmm analysis is one of the few statistical software packages that runs bivariate models to estimate within- and between-individual variance between traits. Bayesian methods, generally referred to as Markov Chain Monte Carlo (MCMC) methods, recently became popular due to developments in computer technology and flexible software programs. We determined the number of iterations, thinning and the burnin period for our models to improve the effective sample size: $10^{6}$ iterations with $10^{5}$ burn-in and a thinning interval of $10^{3}$.

\section{Results}

\section{Experiment with chicks}

\section{Corticosterone level}

Concentrations of faecal corticosterone metabolites in experimental chicks were considerably higher 3 days after implantation than before the manipulation (Kruskal-Wallis test, $H=7.2, d f=2, P=0.027$; Tukey and Kramer post hoc test, $P=0.04$ ) or compared to control chicks (Tukey and Kramer post hoc test, $P=0.04$ ). Experimental chicks before implantation and control chicks had similar levels of faecal corticosterone metabolites (Tukey and Kramer post hoc test, $P=0.97$; Table 1 ). The increase in faecal corticosterone metabolites remained within the physiological range of this species (Kidawa et al. 2014). Chicks implanted with the placebo pellet had similar concentrations before (median $=5.9, Q_{1}-Q_{3}: 4.6-8.9, n=3$ ) and
3 days after implantation $\quad\left(\right.$ median $=6.89, \quad Q_{1}-Q_{3}$ : 6.37-10.56, $n=3$ ).

\section{Begging intensity}

The MCMCglmm analyses showed that after the corticosterone implantation, the number of calls per minute by chicks increased significantly (Table 2; Fig. 1). The duration of the begging session before and after the corticosterone manipulation did not differ significantly; however, the intervals between begging sessions were significantly shorter (Tables 3 and 4; Fig. 1). The effect of the chick was weak, but significant, and explained $13 \%$ of the variation (Table 4).

The MCMCglmm analyses for the interaction between the random factor and fixed factor showed that all chicks reacted in the same way to the manipulation (Tables 5, 6, 7 in the "Appendix"). Moreover, MCMCglmm analyses testing the co-variance between the random factor and fixed factor showed that the effect of the chick was the same before and after corticosterone manipulation (Tables 5, 6, 7 in "Appendix").

\section{Chick development}

The body mass of control and experimental chicks did not differ at the beginning/initial stage of the experiment (when the chicks were 13-15 days old; Wilcoxon rank-sum test, $W=63, P=0.55$; Fig. 2). Experimental and control chicks fledged at the same age (median $=25, Q_{1}-Q_{3}$ : 24-27, $n=12$ and median $=25$ day, $Q_{1}-Q_{3}: 23-25$, $n=16$, respectively; Wilcoxon rank-sum test, $W=19$, $P=0.10)$. However, chicks treated with corticosterone fledged with a significantly higher body mass than control chicks (Wilcoxon rank-sum test, $W=31, P=0.002$; Fig. 2). All chicks fledged successfully.

\section{Experiment with parent birds}

\section{Parental efforts}

Experimental and untreated parent Little Auks differed significantly in chick provisioning (Kruskal-Wallis test,

Table 1 Concentrations of faecal corticosterone metabolites $\left(\mathrm{ng} \mathrm{g}^{-1}\right)$ measured in experimental chicks before the experiment and 3 days after implantation of the corticosterone pellet, and in control chicks

\begin{tabular}{|c|c|c|c|c|c|c|c|c|c|}
\hline & \multicolumn{3}{|c|}{ Before implantation } & \multicolumn{3}{|c|}{ After implantation } & \multicolumn{3}{|l|}{ Control } \\
\hline & Median & $Q_{1}-Q_{3}$ & $n$ & Median & $Q_{1}-Q_{3}$ & $n$ & Median & $Q_{1}-Q_{3}$ & $n$ \\
\hline Faecal corticosterone $\left(\mathrm{ng} \mathrm{g}^{-1}\right)$ & $6.1^{\mathrm{a}}$ & $3.3-11.4$ & 10 & $33.3^{\mathrm{b}}$ & $17.9-49.4$ & 7 & $4.5^{\mathrm{a}}$ & $3.3-14.4$ & 16 \\
\hline
\end{tabular}

Different letters (upper superscript) indicate significant differences between groups 
Table 2 Influence of corticosterone implantation on the call rate (calls/min) with the chick as a random factor analysed using MCMCglmm

\begin{tabular}{lclcr}
\hline & Posterior distribution & Lower 95 \% CI & Upper 95 \% CI & pMCMC \\
\hline Fixed terms & & & & \\
Call rate after implantation & 75.89 & 66.83 & 85.09 & $<0.00001$ \\
Call rate before implantation & -23.44 & -34.91 & -13.69 & $<0.00001$ \\
Random term & & & & \\
Chick* & 62.94 & $43.68 \times 10^{-6}$ & 213.1 & \\
\hline
\end{tabular}

We compared the call rate in 15 chicks before $(n=43$ calls $)$ and after $(n=49$ calls $)$ corticosterone implantation

* The effect of the chick explained $8 \%$ of the variation
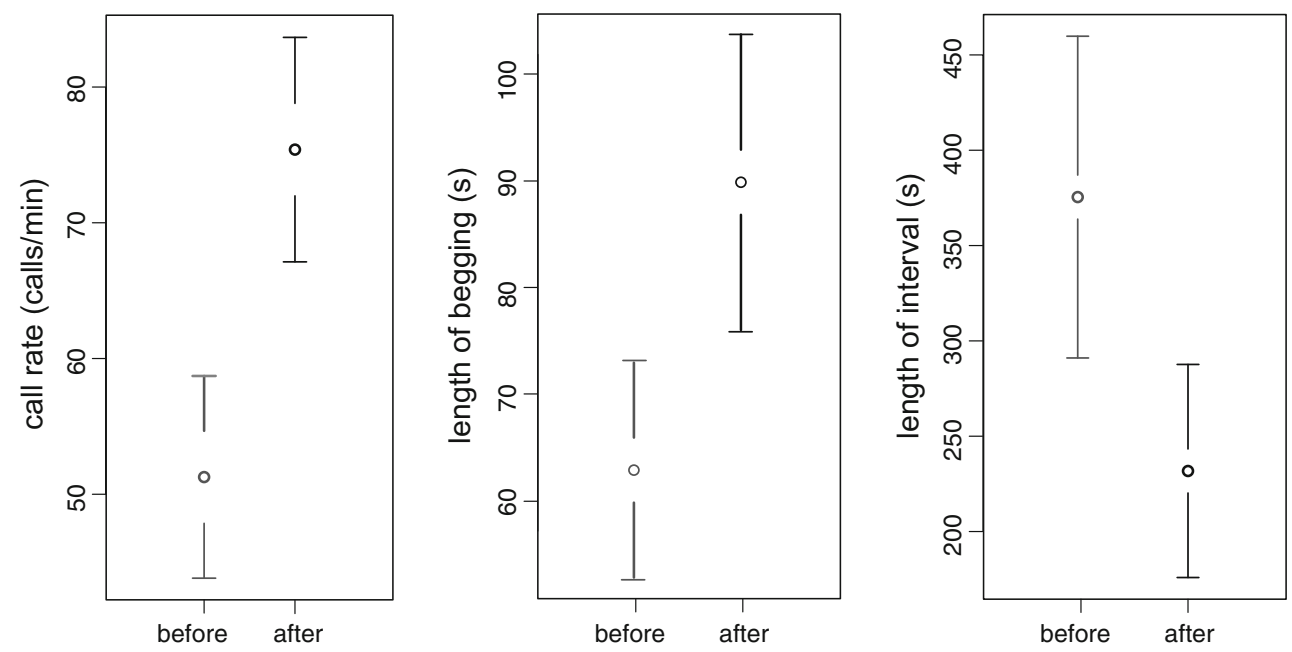

Fig. 1 Begging calls parameters: call rate (left), length of begging sessions (middle) and length of intervals between begging sessions (right) of 15 experimental chicks measured before and after corticosterone implantation (means \pm confidence intervals)

Table 3 Influence of corticosterone implantation on the length of the begging session (s) with the chick as a random factor analysed using MCMCglmm

\begin{tabular}{lcrr}
\hline & Posterior distribution & Lower 95 \% CI & Upper 95\% CI \\
\hline Fixed terms & & & pMCMC \\
Begging length after implantation & 1.634 & 1.5076 & 1.7695 \\
Begging length before implantation & -0.004 & -0.0515 & 0.0407 \\
Random term & & & 0.896 \\
Chick* & 0.0436 & 0.0121 & 0.0931 \\
\hline
\end{tabular}

We compared the length of the begging sessions in 15 chicks before $(n=697$ begging sessions) and after $(n=1100$ begging sessions $)$ corticosterone implantation

* The effect of the chick explained $16 \%$ of the variation

$H=12.0, d f=2, P=0.002)$. Corticosterone-implanted parents fed the chick significantly less frequently than their untreated partners (Tukey and Kramer post hoc test, $p=0.004$ ) and control birds (Tukey and Kramer post hoc test, $P=0.016$; Fig. 3). We observed no significant differences in feeding frequency between control birds and partners of experimental birds (Tukey and Kramer post hoc test, $P=0.601$; Fig. 3 ).

Experimental parents spent less time at the colony (median $\left.=157 \min , Q_{1}-Q_{3}: 52-292 \min , n=12\right)$ than their partners $\left(\right.$ median $=282 \mathrm{~min}, Q_{1}-Q_{3}: 137-425 \mathrm{~min}$, $n=10$ ) and control birds (median $=216 \mathrm{~min}, Q_{1}-Q_{3}$ : 132-435 $\min , n=18)$. However, the differences were not significant (Kruskal-Wallis test, $H=2.82, \quad d f=2$, $P=0.24)$.

\section{Chick development}

Chicks with a corticosterone-implanted parent attained a significantly lower body mass at the mid stage of the 
Table 4 Influence of corticosterone implantation on the length of interval between the begging sessions (s) with the chick as a random factor analysed using MCMCglmm

\begin{tabular}{|c|c|c|c|c|}
\hline & Posterior distribution & Lower $95 \% \mathrm{CI}$ & Upper $95 \%$ CI & pMCMC \\
\hline \multicolumn{5}{|l|}{ Fixed terms } \\
\hline Interval length after implantation & 1.914 & 1.8540 & 1.9678 & $<0.001$ \\
\hline Interval length before implantation & 0.057 & 0.0275 & 0.0814 & $<0.001$ \\
\hline \multicolumn{5}{|l|}{ Random term } \\
\hline Chick* & 0.0097 & 0.0025 & 0.0198 & \\
\hline
\end{tabular}

We compared the length of intervals between the begging sessions in 15 chicks before $(n=679$ intervals $)$ and after $(n=1089$ intervals $)$ corticosterone implantation

* The effect of the chick explained $13 \%$ of the variation

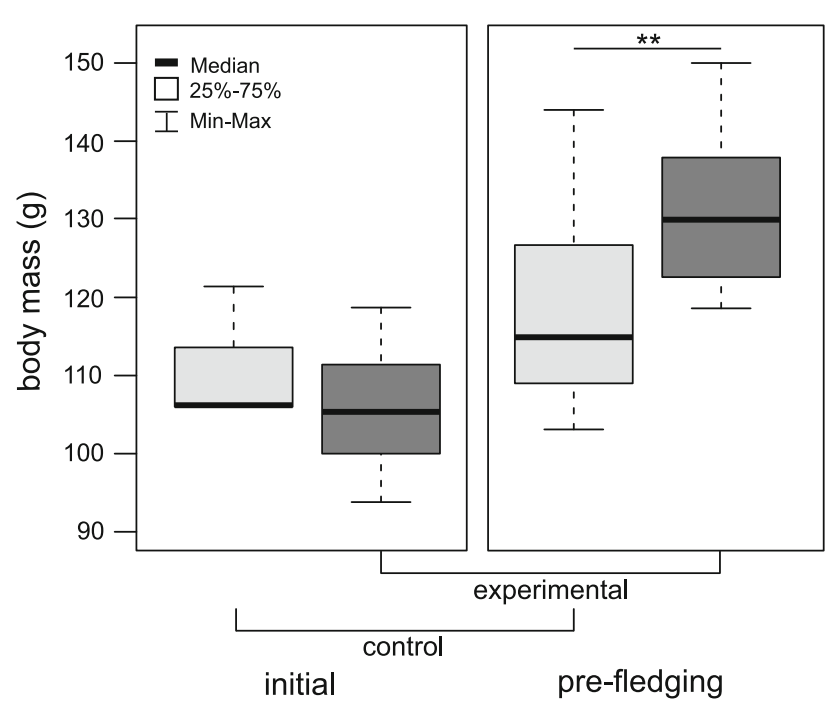

Fig. 2 Body mass of control $(n=16)$ and experimental corticosterone-implanted chicks $(n=15)$. Left, chicks at the beginning of the experiment (initial) and right, after the experiment (pre-fledging)

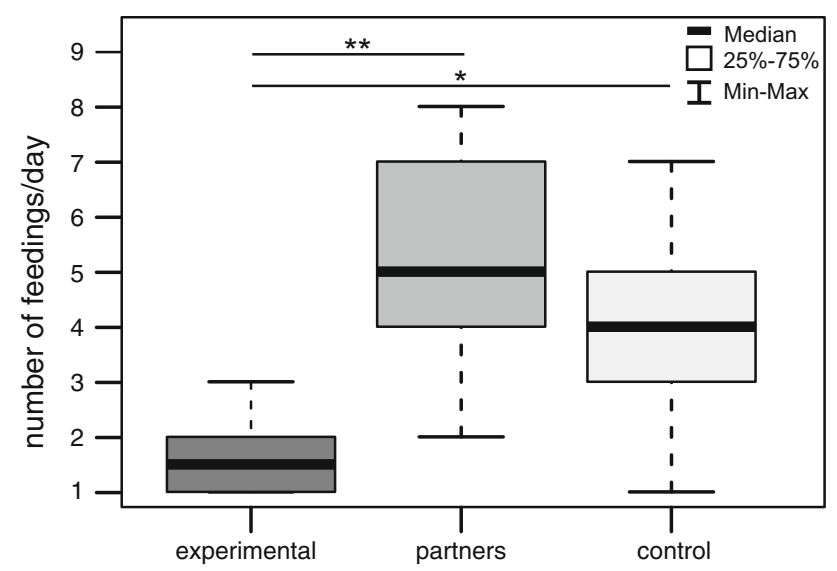

Fig. 3 Number of feedings performed by experimental corticosterone-implanted parent Little Auks $(n=12)$, their partners $(n=10)$ and control birds $(n=18)$ during 24-h continuous observation

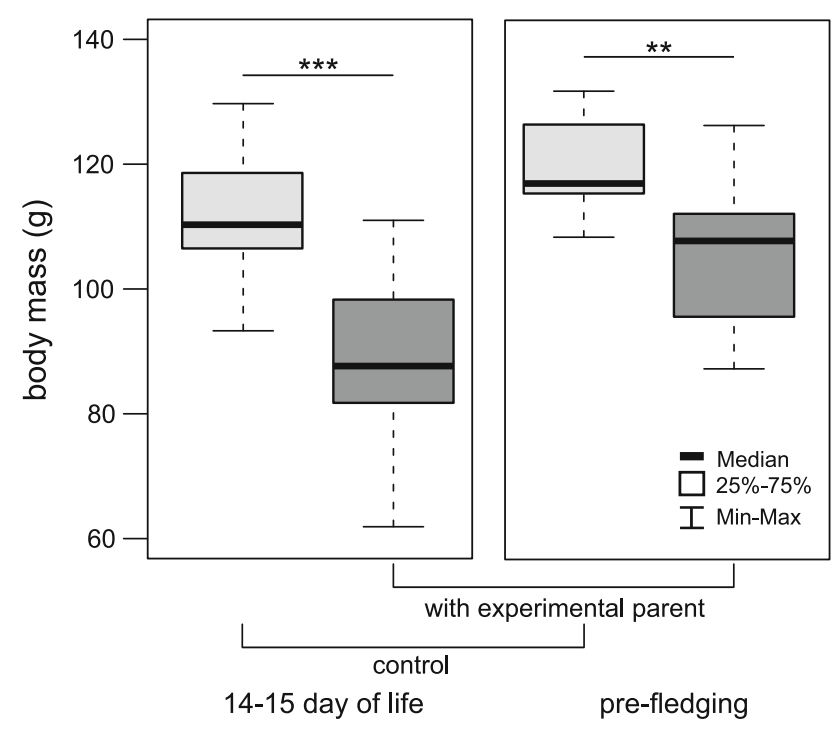

Fig. 4 Body mass of control chicks and chicks with an experimental corticosterone-implanted parent. Left, chicks aged 14-15 days ( $n=20$ control; $n=12$ experimental chicks) and right, at the prefledging stage ( $n=11$ control; $n=11$ experimental chicks)

nesting period (aged 14-15 days; Wilcoxon test, $W=212$, $P=0.0001$; Fig. 4) and at the pre-fledging stage (Wilcoxon test, $W=101, P=0.007$; Fig. 4). Moreover, chicks with a corticosterone-treated parent fledged significantly later than the control chicks (median $=27$ day, $Q_{1^{-}}$ $Q_{3}: 26-28, n=11$ and median $=25, Q_{1}-Q_{3}: 24-26$, $n=11$, respectively; Wilcoxon test, $W=27, P=0.026$ ). All chicks fledged successfully.

\section{Discussion}

In this study, we used the main stress hormone in birds, corticosterone, as an experimental factor to simulate the stress reaction and to investigate changes in the behaviour 
of Little Auk chicks and parent birds. First, we found that Little Auk chicks intensified their begging performance following corticosterone administration, as the call rates were significantly higher and the intervals between begging sessions were significantly shorter. Due to possible individual differences in begging performance between chicks, we compared the same individuals before and after corticosterone treatment, with the chick as a random factor. In colonially breeding species, the discrimination of their own chicks by parents from other conspecific progeny is biologically important (Penney 1968; Beecher et al. 1981; Falls 1982; Insley et al. 2003). Moreover, Little Auk chicks still rely on parental care after fledging (Stempniewicz 2001); thus, the parent-offspring recognition appears to be essential for chick survival. Indeed, the effect of individual chicks on the begging call parameters was significant, but weak. The detailed analyses of acoustic structure of begging call elements might reveal more specific differences between individuals. However, even if differences in acoustic parameters (i.e., frequency distribution) between individuals exist, they may not play a role in signalling body condition, as it was shown in Thin-billed Prions (Duckworth et al. 2009).

A higher intensity of begging related to an elevated stress hormone concentration provides evidence that begging is an honest signal in Little Auks chicks. The results also suggest that begging calls transmit information concerning the chick's body condition and energy requirements to the parents. A significantly higher pre-fledging body mass of corticosterone-implanted chicks, compared to the control chicks, suggests that parents responded accordingly to the chicks' requirements and provided the chicks with more food. Similarly, increased chick begging rates, together with increased parental food provisioning were observed in chicks of the Black-legged Kittiwake (Rissa tridactyla) following an increased corticosterone level (Kitaysky et al. 2001). These results are consistent with those of some previous studies on Little Auks, denoting the ability of parents to increase their feeding frequency (Jakubas et al. 2007; Kwasniewski et al. 2010). It is possible that Little Auks can redirect colony attendance time towards foraging and chick provisioning. However, our experiment with adult birds allowed us to gain insight into how the Little Auks' parental investment decisions may be modified when the parent birds are affected by severe conditions.

In the second experiment, we found that corticosteroneimplanted parent Little Auks fed their chicks significantly less frequently than their partners and the control birds. In consequence, chicks with one experimental parent attained significantly lower body mass and fledged significantly later than chicks of untreated parents. Apart from a reduced chick feeding frequency, experimental parent birds spent slightly more time out of the colony, probably in foraging activity. During the chick-rearing period, Little Auks adopt a bimodal foraging strategy, where they make several short trips (lasting ca $2 \mathrm{~h}$ ) and then a single long trip (usually lasting $>10 \mathrm{~h}$ and primarily devoted to self-feeding; Steen et al. 2007; Welcker et al. 2009; Wojczulanis-Jakubas et al. 2010; Welcker et al. 2012). Birds breeding in low-quality foraging habitat perform longer self-feeding trips (even 17-20 h; Welcker et al. 2009; Brown et al. 2012). Accordingly, parent birds with experimentally increased levels of circulating corticosterone presumably made longer self-feeding trips. The length of the long foraging trip and the impact on frequency of short trips could not be ascertained during the 24-h observation period. Nonetheless, a lower provisioning frequency of parents implanted with corticosterone compared to their partners and control birds was evident in our study. Corticosterone orchestrates many physiological and behavioural responses to promote survival, e.g., by mobilizing energy reserves (Axelrod and Reisine 1984; Sapolsky et al. 2000) and increasing locomotor activity (Robin et al. 1998; Landys et al. 2006). Further, the elevated corticosterone levels in parent birds might reduce chick provisioning and even trigger brood desertion (Landys et al. 2006; Angelier et al. 2009). Our results correspond with those of previous studies on Little Auks, which showed that in poor foraging habitat conditions, chick feeding frequency and chick body mass substantially decreased (Harding et al. 2009; Kidawa et al. 2015). A lower body mass has been previously documented in chicks with parents that had their feathers clipped or carried data loggers (Harding et al. 2009; Kidawa et al. 2012). A limitation of our study is the fact that the additional acute stress caused by implanting pellets is indistinguishable from the exogenous corticosterone dissolving from the pellet. Also, we did not consider the possibility of a negative feedback that down-regulates the adrenocortical stress response (Akana et al. 1992; Rich and Romero 2005; Busch et al. 2008). Although we cannot exclude that administration of exogenous corticosterone attenuated the endogenous corticosterone release in response to stress (Akana et al. 1992; Rich and Romero 2005; Busch et al. 2008), a high dose of exogenous corticosterone could replace endogenous corticosterone production (Fusani 2008). Pellet doses used in our study (scaled to the body mass of Little Auks) corresponded to doses, which 
successfully increased levels of circulating corticosterone in birds in other experimental studies (Romero et al. 2005; Bourgeon and Raclot 2006; Müller et al. 2009a, b; Spée et al. 2011). Continuous monitoring of corticosterone levels in experimental birds throughout the whole study period would strengthen our conclusions (Fusani 2008). Nonetheless, even a short-term experimental increase of corticosterone level may suppress parental behaviour via reduction of prolactin secretion (Angelier et al. 2009). Marked differences in chick body mass and fledging age between chicks with one experimental parent and chicks of untreated parents confirm reduced parental investment of corticosterone-treated birds over the course of our study.

Some authors have suggested that a reduction in the feeding rate of manipulated birds might be fully or partially compensated for by their non-manipulated partners (Paredes et al. 2005; Harding et al. 2009). Indeed, the results for corticosterone-implanted chicks showed that parents apparently were able to increase provisioning (as reflected in higher mass of corticosterone-implanted chicks at fledging). Nonetheless, in the experiment with corticosterone-implanted parents, we observed no significant increase in the feeding rate of the untreated partner. However, the delivery rate by the partners was one of the highest observed in the studied colony and other Little Auk colonies to date (Stempniewicz and Jezierski 1987; Jakubas et al. 2007; Welcker et al. 2009; Karnovsky et al. 2010; Kwasniewski et al. 2010; Grémillet et al. 2012; Kidawa et al. 2012; Hovinen et al. 2014; Kidawa et al. 2015). It is likely that these birds provisioned chicks at near their maximal rates. Considering the high costs required to sustain themselves (the high cost of flight, foraging and high metabolic rates), Little Auks might often function near to their maximum performance limits. It has been suggested that the flexibility of time and energy budgets of breeding seabirds allows them to adjust food delivery rates according to offspring energy demands, but only when foraging conditions are favourable (Weimerskirch et al. 2001; Litzow and Piatt 2003). For instance, in Common Guillemots, compensation for changes in food quality could occur in a situation in which switching to alternative prey was possible and food quantity was high (Kadin et al. 2016). However, in Little Auks, the foraging efficiency is strongly determined by the quality and not the quantity of available prey species (Kidawa et al. 2015). In contrast to larger species, small seabirds have fewer reserves to allow their mass to decrease temporarily; thus, their "safety margin for breeding" is relatively low (Duriez et al. 2000). Therefore, we believe that the increase in the chick provisioning rate to compensate for either worse foraging conditions (Jakubas et al. 2007; Kwasniewski et al. 2010) or a reduced feeding rate of the burdened partner (Harding et al. 2009) is possible to some extent; however, it is limited by the birds' time and energy budget, and greatly depends on the food resources available.

In conclusion, we found that begging constitutes an adaptive mechanism that guards against the decrease in the chicks' body condition during stressful periods for Little Auks. On the other hand, we do not know whether and to what extent the increased corticosterone level compromises the birds' future fitness. A nutritional deficit during development can affect the quality of nestlings, which is likely to compromise their cognitive abilities, immune function, and results in increased mortality (Kitaysky et al. 2003, 2006; Loiseau et al. 2008). Therefore, when the fitness costs are higher than the benefits, a reduced parental investment might be adaptive (Angelier et al. 2009). Even though our results suggest that the provisioning rate in long-lived Little Auks can be regulated according to the chick's needs (expressed by the intensity of the begging display), it appears to be primarily determined by the parents' body state. The results support the idea that Little Auks will decrease their parental effort and redirect the available energy towards self-maintenance when their energetic state approaches a low threshold.

Acknowledgments We wish to thank Lech Stempniewicz and anonymous reviewers for providing valuable comments on the manuscript, Izabela Kulaszewicz for assistance in the field, and Szymon Drobniak for recommending and explaining the MCMCglmm analyses in R. This study was conducted under permits of the Governor of Svalbard and the Norwegian Animal Research Committee. The project was supported financially by the resources from National Science Centre in Poland based on the decision (DEC2011/01/N/NZ8/04569) and University of Gdańsk (538-L120-B924$15)$.

Open Access This article is distributed under the terms of the Creative Commons Attribution 4.0 International License (http://crea tivecommons.org/licenses/by/4.0/), which permits unrestricted use, distribution, and reproduction in any medium, provided you give appropriate credit to the original author(s) and the source, provide a link to the Creative Commons license, and indicate if changes were made. 


\title{
Appendix
}

\author{
See Tables 5, 6, 7 .
}

Table 5 Influence of corticosterone implantation on the call rate (no calls $/ \mathrm{min}$ ) with the chick as a random factor analysed using MCMCglmm: (1) with the interaction between the random and the fixed factor; (2) testing the covariance between the variables

$\begin{array}{llll}\text { Posterior distribution } & \text { Lower } 95 \% \mathrm{CI} & \text { Upper } 95 \% \mathrm{CI} & \text { pMCMC }\end{array}$

(1) Interaction

Call rate after implantation $\times$ chick

Call rate before implantation $\times$ chick

Interval length after implantation

Interval length before implantation

(2) Covariance

Call rate after implantation: call rate after implantation $\times$ chick

Call rate before implantation: call rate after implantation $\times$ chick

Call rate after implantation: call rate before implantation $\times$ chick

Call rate before implantation: call rate before

implantation $\times$ chick

Interval length after implantation

Interval length before implantation

$\begin{array}{rrrr}0.0668 & 0.0165 & 0.1422 & \\ 0.0287 & 0.0033 & 0.0653 & \\ 1.6489 & 1.5065 & 1.8047 & <0.001 \\ -0.0396 & -0.2220 & 0.1205 & 0.0622 \\ & & & \\ 0.0675 & 0.0188 & 0.1428 & \\ 0.0274 & -0.0061 & 0.0673 & \\ 0.0274 & -0.0061 & 0.0673 & \\ 0.0301 & 0.0030 & 0.0769 & \\ & & & \\ 1.6498 & 1.4885 & 1.7957 & 0.001 \\ -0.0346 & -0.1526 & 0.0983 & \end{array}$

We compared the call rate in 15 chicks before $(n=43$ calls) and after $(n=49$ calls) corticosterone implantation

Table 6 Influence of corticosterone implantation on the length of the begging session (s) with the chick as a random factor analysed using MCMCglmm: (1) with the interaction between the random and the fixed factor; (2) testing the covariance between the variables

\begin{tabular}{|c|c|c|c|c|}
\hline & $\begin{array}{l}\text { Posterior } \\
\text { distribution }\end{array}$ & $\begin{array}{l}\text { Lower } 95 \% \\
\text { CI }\end{array}$ & $\begin{array}{l}\text { Upper } 95 \% \\
\text { CI }\end{array}$ & pMCMC \\
\hline \multicolumn{5}{|l|}{ (1) Interaction } \\
\hline Begging length after implantation $\times$ chick & 0.0686 & 0.0195 & 0.1492 & \\
\hline Begging length before implantation $\times$ chick & 0.0288 & 0.0029 & 0.0727 & \\
\hline Interval length after implantation & 1.6493 & 1.4959 & 1.8047 & $<0.001$ \\
\hline Interval length before implantation & -0.0387 & -0.2318 & 0.1426 & 0.664 \\
\hline \multicolumn{5}{|l|}{ (2) Covariance } \\
\hline $\begin{array}{l}\text { Begging length after implantation: begging length after } \\
\text { implantation } \times \text { chick }\end{array}$ & 0.0691 & 0.0141 & 0.1426 & \\
\hline $\begin{array}{l}\text { Begging length before implantation: begging length after } \\
\text { implantation } \times \text { chick }\end{array}$ & 0.0292 & -0.0018 & 0.0729 & \\
\hline $\begin{array}{l}\text { Begging length after implantation: begging length before } \\
\text { implantation } \times \text { chick }\end{array}$ & 0.0292 & -0.0018 & 0.0729 & \\
\hline $\begin{array}{l}\text { Begging length before implantation: begging length before } \\
\text { implantation } \times \text { chick }\end{array}$ & 0.0299 & 0.0039 & 0.0708 & \\
\hline Interval length after implantation & 1.6505 & 1.5066 & 1.8249 & $<0.001$ \\
\hline Interval length before implantation & -0.0369 & -0.1655 & 0.1000 & 0.536 \\
\hline
\end{tabular}

We compared the length of the begging sessions in 15 chicks before $(n=697$ begging sessions) and after ( $n=1100$ begging sessions) corticosterone implantation 
Table 7 Influence of corticosterone implantation on the length of interval between the begging sessions (s) with chick as a random factor analysed using MCMCglmm: (1) with the interaction between the random and the fixed factor; (2) testing the covariance between the variables

\begin{tabular}{|c|c|c|c|c|}
\hline & $\begin{array}{l}\text { Posterior } \\
\text { distribution }\end{array}$ & $\begin{array}{l}\text { Lower } 95 \% \\
\text { CI }\end{array}$ & $\begin{array}{l}\text { Upper } 95 \% \\
\text { CI }\end{array}$ & pMCMC \\
\hline \multicolumn{5}{|l|}{ (1) Interaction } \\
\hline Interval length after implantation $\times$ chick & 0.0095 & 0.0020 & 0.0207 & \\
\hline Interval length before implantation $\times$ chick & 0.0131 & 0.0030 & 0.0297 & \\
\hline Interval length after implantation & 1.9180 & 1.8567 & 1.9750 & $<0.001$ \\
\hline Interval length before implantation & 0.0650 & -0.0227 & 0.1579 & 0.158 \\
\hline \multicolumn{5}{|l|}{ (2) Covariance } \\
\hline $\begin{array}{l}\text { Interval length after implantation: interval length after } \\
\text { implantation } \times \text { chick }\end{array}$ & 0.0093 & 0.0025 & 0.0199 & \\
\hline $\begin{array}{l}\text { Interval length before implantation: interval length after } \\
\text { implantation } \times \text { chick }\end{array}$ & 0.0066 & -0.0014 & 0.0163 & \\
\hline $\begin{array}{l}\text { Interval length after implantation: interval length before } \\
\text { implantation } \times \text { chick }\end{array}$ & 0.0066 & -0.0013 & 0.0163 & \\
\hline $\begin{array}{l}\text { Interval length before implantation: interval length before } \\
\text { implantation } \times \text { chick }\end{array}$ & 0.0129 & 0.0029 & 0.0276 & \\
\hline Interval length after implantation & 1.9155 & 1.8658 & 1.9769 & $<0.001$ \\
\hline Interval length before implantation & 0.0668 & 0.0106 & 0.1380 & 0.042 \\
\hline
\end{tabular}

We compared the length of intervals between the begging sessions in 15 chicks before $(n=679$ intervals $)$ and after $(n=1089$ intervals $)$ corticosterone implantation

\section{References}

Akana SF, Scribner KA, Bradbury MJ et al (1992) Feedback sensitivity of the rat hypothalamo-pituitary-adrenal axis and its capacity to adjust to exogenous corticosterone. Endocrinology 131:585-594

Angelier F, Clement-Chastel C, Welcker J et al (2009) How does corticosterone affect parental behaviour and reproductive success? A study of prolactin in black-legged kittiwakes. Funct Ecol 23:784-793. doi:10.1111/j.1365-2435.2009.01545.x

Axelrod J, Reisine TD (1984) Stress hormones: their interaction and regulation (Review). Science 224:452-459. doi:10.1126/science. 6143403

Beecher MD, Beecher IM, Hahn S (1981) Parent-offspring recognition in bank swallows (Riparia riparia): II. Development and acoustic basis. Anim Behav 29:95-101. doi:10.1016/S00033472(81)80156-X

Bioacoustics Research Program (2013) Raven Pro: interactive sound analysis software (Version 1.5) [Computer software]. Ithaca, NY: The Cornell Lab of Ornithology.http://www.birds.cornell. edu/raven. Accessed 20 Sept 2015

Bonier F, Martin PR, Moore IT, Wingfield JC (2009) Do baseline glucocorticoids predict fitness? Trends Ecol Evol 24:634-642. doi:10.1016/j.tree.2009.04.013

Bourgeon S, Raclot T (2006) Corticosterone selectively decreases humoral immunity in female eiders during incubation. J Exp Biol 209:4957-4965. doi:10.1242/jeb.02610

Brown ZW, Welcker J, Harding AMA et al (2012) Divergent diving behavior during short and long trips of a bimodal forager, the little auk Alle alle. J Avian Biol 43:215-226. doi:10.1111/j. 1600-048X.2012.05484.x

Burger AE, Piatt JF (1990) Flexible time budgets in breeding Common Murres: buffers against variable prey abundance. Stud Avian Biol 14:71-83
Busch DS, Sperry TS, Wingfield JC, Boyd EH (2008) Effects of repeated, short-term, corticosterone administration on the hypothalamo-pituitary-adrenal axis of the white-crowned sparrow (Zonotrichia leucophrys gambelii). Gen Comp Endocrinol 158:211-223. doi:10.1016/j.ygcen.2008.06.004

Charif RA, Waack AM, Strickman LM (2010) Raven Pro 1.4 User's Manual. Cornell Lab of Ornithology, Ithaca, NY

Cotton PA, Kacelnik A, Wright J (1996) Chick begging as a signal: are nestlings honest? Behav Ecol 7:178-182. doi:10.1093/ beheco/7.2.178

Duckworth A, Masello JF, Mundry R, Quillfeldt P (2009) Functional characterization of begging calls in Thin-billed Prions Pachyptila belcheri chicks. Acta Ornithol 44:127-137. doi:10.3161/ 000164509 X482704

Duriez O, Weimerskirch H, Fritz H (2000) Regulation of chick provisioning in the thin-billed prion: an interannual comparison and manipulation of parents. Can J Zool 78:1275-1283. doi:10. 1139/z00-063

Eilertsen K, Barrett RT, Torstein P (2008) Diet, growth and early survival of Atlantic Puffin (Fratercula arctica) chicks in North Norway. Waterbirds 31:107-114. doi:10.1675/1524-4695(2008) 31[107:DGAESO]2.0.CO;2

Falls BJ (1982) Individual recognition by sound in birds. In: Kroodsma DE, Miller EH (eds) Acoustic communication in birds: song learning and its consequences, vol 2. Academic Press, New York, pp 237-278

Fusani L (2008) Endocrinology in field studies: problems and solutions for the experimental design. Gen Comp Endocrinol 157:249-253. doi:10.1016/j.ygcen.2008.04.016

Grémillet D, Welcker J, Karnovsky N et al (2012) Little auks buffer the impact of current Arctic climate change. Mar Ecol Prog Ser 454:197-206. doi:10.3354/meps09590

Hadfield JD (2010) MCMC methods for multi-response generalized linear mixed models: the MCMCglmm R package. J Stat Softw 33:1-22 
Harding AMA, Kitaysky AS, Hall ME et al (2009) Flexibility in the parental effort of an Arctic-breeding seabird. Funct Ecol 23:348-358. doi:10.1111/j.1365-2435.2008.01488.x

Harding AMA, Van Pelt TI, Lifjeld JT, Mehlum F (2004) Sex differences in Little Auk Alle alle parental care: transition from biparental to paternal-only care. Ibis 146:642-651. doi:10.1111/ j.1474-919x.2004.00297.x

Harding AMA, Welcker J, Steen $\mathrm{H}$ et al (2011) Adverse foraging conditions may impact body mass and survival of a high Arctic seabird. Oecologia 167:49-59. doi:10.1007/s00442-011-1971-7

Hovinen JEH, Wojczulanis-Jakubas K, Jakubas D et al (2014) Fledging success of little auks in the high Arctic: do provisioning rates and the quality of foraging grounds matter? Polar Biol 37:665-674. doi:10.1007/s00300-014-1466-1

Insley SJ, Paredes R, Jones IL (2003) Sex differences in razorbill Alca torda parent-offspring vocal recognition. J Exp Biol 206:25-31. doi: $10.1242 /$ jeb.00072

Isaksen K (1995) The breeding population of Little Auk (Alle alle) in colonies in Hornsund and northwestern Spitsbergen. In: Isaksen $\mathrm{K}$, Bakken V (eds) Seabird populations in the northern Barents Sea. Norsk Polarinstitutt, Oslo, pp 49-57

Jakubas D, Wojczulanis-Jakubas K, Walkusz W (2007) Response of dovekie to changes in food availability. Waterbirds 30:421-428. doi:10.1675/1524-4695(2007)030[0421:RODTCI]2.0.CO;2

Kadin M, Olsson O, Hentati-Sundberg J et al (2016) Common Guillemot Uria aalge parents adjust provisioning rates to compensate for low food quality. Ibis 158:167-178. doi:10. 1111/ibi.12335

Karnovsky N, Harding A, Walkusz W et al (2010) Foraging distributions of little auks Alle alle across the Greenland Sea: implications of present and future Arctic climate change. Mar Ecol Prog Ser 415:283-293. doi:10.3354/meps08749

Kidawa D, Jakubas D, Wojczulanis-Jakubas K et al (2012) The effects of loggers on the foraging effort and chick-rearing ability of parent little auks. Polar Biol 35:909-917. doi:10.1007/s00300$011-1136-5$

Kidawa D, Jakubas D, Wojczulanis-Jakubas K et al (2015) Parental efforts of an Arctic seabird, the little auk Alle alle, under variable foraging conditions. Mar Biol Res 11:349-360. doi:10.1080/ 17451000.2014.940974

Kidawa D, Wojczulanis-Jakubas K, Jakubas D et al (2014) Variation in faecal corticosterone metabolites in an Arctic seabird, the Little Auk (Alle alle) during the nesting period. Polar Biol 37:641-649. doi:10.1007/s00300-014-1464-3

Kitaysky AS, Kitaiskaia EV, Piatt JF, Wingfield JC (2003) Benefits and costs of increased levels of corticosterone in seabird chicks. Horm Behav 43:140-149. doi:10.1016/S0018-506X(02)00030-2

Kitaysky AS, Kitaiskaia EV, Piatt JF, Wingfield JC (2006) A mechanistic link between chick diet and decline in seabirds? Proc R Soc B Biol Sci 273:445-450. doi:10.1098/rspb.2005. 3351

Kitaysky AS, Wingfield JC, Piatt JF (2001) Corticosterone facilitates begging and affects resource allocation in the black-legged kittiwake. Behav Ecol 12:619-625. doi:10.1093/beheco/12.5.619

Konarzewski M, Taylor JRE, Gabrielsen GW (1993) Chick energy requirements and adult energy expenditures of dovekies (Alle alle). Auk 110:343-353

Kwasniewski S, Gluchowska M, Jakubas D et al (2010) The impact of different hydrographic conditions and zooplankton communities on provisioning Little Auks along the West coast of Spitsbergen. Prog Oceanogr 87:72-82. doi:10.1016/j.pocean.2010.06.004

Kwasniewski S, Gluchowska M, Walkusz W et al (2012) Interannual changes in zooplankton on the West Spitsbergen Shelf in relation to hydrography and their consequences for the diet of planktivorous seabirds. ICES J Mar Sci 69:890-901
Landys MM, Ramenofsky M, Wingfield JC (2006) Actions of glucocorticoids at a seasonal baseline as compared to stressrelated levels in the regulation of periodic life processes. Gen Comp Endocrinol 148:132-149. doi:10.1016/j.ygcen.2006.02. 013

Litzow MA, Piatt JF (2003) Variance in prey abundance influences time budgets of breeding seabirds: evidence from pigeon guillemots Cepphus columba. J Avian Biol 34:54-64. doi:10. 1034/j.1600-048X.2003.02995.x

Loiseau C, Sorci G, Dano S, Chastel O (2008) Effects of experimental increase of corticosterone levels on begging behavior, immunity and parental provisioning rate in house sparrows. Gen Comp Endocrinol 155:101-108. doi:10.1016/j.ygcen.2007.03.004

Möstl E, Maggs JL, Schrötter G et al (2002) Measurement of cortisol metabolites in faeces of ruminants. Vet Res Commun 26:127-139

Möstl E, Palme R (2002) Hormones as indicators of stress. Domest Anim Endocrinol 23:67-74. doi:10.1016/S0739-7240(02)00146-7

Müller C, Almasi B, Roulin A et al (2009a) Effects of corticosterone pellets on baseline and stress-induced corticosterone and corticosteroid-binding-globulin. Gen Comp Endocrinol 160:59-66. doi:10.1016/j.ygcen.2008.10.018

Müller MS, Goerlich VC, Roelofs Y et al (2009b) Experimentally simulating chronic stress in birds: a re-evaluation of corticosterone treatment methods. In: Manipulative mothers: maternal steroid hormones and avian offspring sex ratio. Doctoral Thesis. Groningen, pp 93-110

Palme R, Möstl E (1997) Measurement of cortisol metabolites in faeces of sheep as a parameter of cortosol concentration in blood. Z Saugetierkd Int J Mamm Biol 62:192-197

Palme R, Touma C, Arias N et al (2013) Steroid extraction: Get the best out of faecal samples. Wien Tierärztl Monat Vet Med Austria 100:238-246

Paredes R, Jones IL, Boness DJ (2005) Reduced parental care, compensatory behaviour and reproductive costs of thick-billed murres equipped with data loggers. Anim Behav 69:197-208. doi:10.1016/j.anbehav.2003.12.029

Penney RL (1968) Territorial and Social Behavior in the Adélie Penguin. In: Austin OL (ed) Antarctic bird studies. American Geophysical Union, Washington, pp 83-131

Pohlert T (2014) The pairwise multiple comparison of mean ranks package (PMCMR). https://cran.r-project.org/web/packages/ PMCMR/vignettes/PMCMR.pdf. Accessed 20 Jan 2016

Quillfeldt P, Masello JF, Strange IJ, Buchanan KL (2006) Begging and provisioning of thin-billed prions, Pachyptila belcheri, are related to testosterone and corticosterone. Anim Behav 71:1359-1369. doi:10.1016/j.anbehav.2005.09.015

R Core Team (2015) R: A language and environment for statistical computing. $\mathrm{R}$ foundation for statistical computing, Vienna, Austria. URL http://www.R-project.org/. Accessed 10 Oct 2015

Rich EL, Romero LM (2005) Exposure to chronic stress downregulates corticosterone responses to acute stressors. Am J Physiol Regul Integr Comp Physiol 288:R1628-R1636. doi:10.1152/ ajpregu.00484.2004

Ricklefs RE (1977) On the evolution of reproductive strategies in birds: reproductive Effort. Am Nat 111:453-478

Robin JP, Boucontet L, Chillet P, Groscolas R (1998) Behavioral changes in fasting emperor penguins: evidence for a "refeeding signal" linked to a metabolic shift. Am J Physiol 274:R746R753

Romero LM (2002) Seasonal changes in plasma glucocorticoid concentrations in free-living vertebrates. Gen Comp Endocrinol 128:1-24. doi:10.1016/S0016-6480(02)00064-3

Romero LM, Strochlic D, Wingfield JC (2005) Corticosterone inhibits feather growth: potential mechanism explaining seasonal down regulation of corticosterone during molt. Comp Biochem Physiol 
Part A Mol Integr Physiol 142:65-73. doi:10.1016/j.cbpa.2005. 07.014

Sapolsky RM, Romero LM, Munck AU (2000) How do glucocorticoids influence stress responses? Preparative actions. Endocr Rev 21:55-89. doi:10.1210/er.21.1.55

Shini S, Shini A, Huff GR (2009) Effects of chronic and repeated corticosterone administration in rearing chickens on physiology, the onset of lay and egg production of hens. Physiol Behav 98:73-77. doi:10.1016/j.physbeh.2009.04.012

Smiseth PT, Scott MP, Andrews C (2011) Hormonal regulation of offspring begging and mediation of parent-offspring conflict. Anim Behav 81:507-517. doi:10.1016/j.anbehav.2010.11.029

Spée M, Marchal L, Lazin D et al (2011) Exogenous corticosterone and nest abandonment: a study in a long-lived bird, the Adélie penguin. Horm Behav 60:362-370. doi:10.1016/j.yhbeh.2011. 07.003

Stearns SC (1992) The evolution of life histories. Oxford University Press, New York

Steen H, Vogedes D, Broms F et al (2007) Little auks (Alle alle) breeding in a High Arctic fjord system: bimodal foraging strategies as a response to poor food quality? Polar Res 26:118-125. doi:10.1111/j.1751-8369.2007.00022.x

Stempniewicz L (1981) Breeding biology of the Little Auk, Plautus alle in the Hornsund region, SW Spitsbergen. Acta Ornithol 18:141-165

Stempniewicz L (2001) Alle alle little auk. The journal of the Birds of the Western Palearctic, BWP Update. Oxford University, Oxford, pp 175-201
Stempniewicz L, Jezierski J (1987) Incubation Shifts and Chick Feeding Rate in the Little Auk Alle alle in Svalbard. Ornis Scand 18:152-155. doi: $10.2307 / 3676853$

Vallarino A, Wingfield JC, Drummond H (2006) Does extra corticosterone elicit increased begging and submissiveness in subordinate booby (Sula nebouxii) chicks? Gen Comp Endocrinol 147:297-303. doi:10.1016/j.ygcen.2006.01.016

Weimerskirch H, Zimmermann L, Prince PA (2001) Influence of environmental variability on breeding effort in a long-lived seabird, the yellow-nosed albatross. Behav Ecol 12:22-30

Welcker J, Beiersdorf A, Varpe Ø, Steen H (2012) Mass fluctuations suggest different functions of bimodal foraging trips in a centralplace forager. Behav Ecol 23:1372-1378. doi:10.1093/beheco/ $\operatorname{ars} 131$

Welcker J, Harding AMA, Karnovsky NJ et al (2009) Flexibility in the bimodal foraging strategy of a high Arctic alcid, the little auk Alle alle. J Avian Biol 40:388-399. doi:10.1111/j.1600-048X. 2008.04620.x

Williams CT, Kitaysky AS, Buck CL (2008) Food restricted Tufted Puffin (Fratercula cirrhata) nestlings increase vocal activity during handling without modulating total or free corticosterone y. J Ornithol 149:277-283. doi:10.1007/s10336-008-0274-1

Wojczulanis-Jakubas K, Jakubas D (2012) When and why does my mother leave me? the question of brood desertion in the Dovekie (Alle Alle). Auk 129:632-637. doi:10.1525/auk.2012.12095

Wojczulanis-Jakubas K, Jakubas D, Karnovsky NJ, Walkusz W (2010) Foraging strategy of little auks under divergent conditions on feeding grounds. Polar Res 29:22-29. doi:10.1111/j.17518369.2009.00145.x 